\title{
PULMONARY EMBOLISM DURING ANAESTHESIA: CASE REPORT
}

\author{
V.M. Divekar, B.M. Kamdar and S.N. Pansare
}

\begin{abstract}
Pulmonary embolism of the left lower lobe occurring during operation was diagnosed and treated successfully.
\end{abstract}

KEy WORDS: ANAESTHESIA, COMPLICATIONS, pulmonary embolism.

THE INCIDENCE of pulmonary embolism detectable clinically is less than that revealed at postmortem (10.15 per cent). ${ }^{1,2}$ The fact that pulmonary embolism is missed more often than it is diagnosed may be explained by the occurrence of non-specific signs and symptons in the majority of patients. The lack of laboratory tests may be another major factor in the low incidence of antemortem diagnosis. Diagnosis is empirical in many cases when it is suspected. A case of pulmonary embolism which was diagnosed by chest radiography and electrocardiogram during anaesthesia is reported.

\section{CASE REPORT}

A 60 year old obese female was admitted on 31st August 1979 with a complaint of backache. Laminectomy was to be done on 13th October 1979. There was a history of hypertension and antihypertensive therapy one month before operation. Preoperatively her blood pressure was $170 / 80 \mathrm{mmHg}$, pulse $96 / \mathrm{min}$, respiratory and cardiovascular systems were clinically normal. Preoperative haemoglobin was $13 \mathrm{~g}$ per cent, blood sugar (F) $105 \mathrm{mg}$ per cent, chest $\mathrm{X}$-ray was normal, the electrocardiogram showed sinus tachycardia and low voltage.

The patient was given atropine $0.6 \mathrm{mg}$ intramuscularly one-half hour before operation. After induction of anaesthesia with diazepam $10 \mathrm{mg}$, thiopentone $200 \mathrm{mg}$ and succinylcholine $50 \mathrm{mg}$ intravenously the cords were sprayed with four per cent xylocaine and the trachea was intubated with an $8.5 \mathrm{~mm}$ Magill cuffed tracheal tube. Anaesthesia was maintained with nitrous oxide,

V.M. Divekar, M.D., D.A., Professor and Head; B.M. Kamdar, M.D., D.A., Assistant Professor; S.M. Pansare, M.D., D.A., Lecturer; Department of Anaesthesia, T.N. Medical College \& B.Y.L. Nair CH. Hospital, Dr. A.L. Nair Road, Bombay 400008 , India. oxygen and d-tubocurarine $20 \mathrm{mg}$ and ventilation was controlled. Ten minutes later the patient was placed in the prone position. The blood pressure fell from $150 / 80 \mathrm{mmHg}$ to $120 / 80 \mathrm{mmHg}$ and at the same time resistance to ventilation was noted and rhonchi were heard all over, but more on the left side of the chest. The blood pressure next fell to $70 \mathrm{mmHg}$ systolic and after five minutes the radial pulse disappeared. Mephentermine $30 \mathrm{mg}$ was given intravenously and the patient was turned to the supine position. Cardiac standstill was suspected and external cardiac massage was started with intermittent positive pressure ventilation with 100 per cent oxygen. The pulse and heart sounds reappeared immediately. Sodium bicarbonate $(200 \mathrm{ml}$ of 7.4 per cent solution), hydrocortisone $100 \mathrm{mg}$ and mannitol $(200 \mathrm{ml}$ of 20 per cent solution) were given intravenously.

The blood pressure was now $170 / 70 \mathrm{mmHg}$ and pulse rate $140 / \mathrm{min}$. Intermittent positive pressure ventilation was continued for an hour. The trachea was extubated after reversal of the muscle relaxant with atropine $0.5 \mathrm{mg}$ and neostigmine 2.5 mg intravenously. 8 The patient was restless. Rales and rhonchi were heard at the base of the left lung and expiration was prolonged.

Two hours after induction the trachea was re-intubated and IPPV was started with oxygen. Aminophylline $200 \mathrm{mg}$, hydrocortisone $200 \mathrm{mg}$ and furosimide $20 \mathrm{mg}$ were given. The rhonchi disappeared. However coarse râles were still present in the base of the left lung.

An electrocardiogram at this time showed sinus tachycardia and left anterior hemiblock (LAHB) (Figure 3). Chest $x$-ray revealed a relatively avascular zone at the left base. There was a possibility of pulmonary embolism (Figure 1). Arterial blood samples showed $\left[\mathrm{H}^{+}\right] \quad 46.77$ $\mathrm{nmol} / 1$ (pH 7.33), $\mathrm{Pa}_{0_{2}} 6 \mathrm{kPa}(120 \mathrm{mmHg}), \mathrm{Pa}_{\mathrm{CO}_{2}}$ $4.9 \mathrm{kPa}(37 \mathrm{~mm} \mathrm{Hg}$ ), K $4.6 \mathrm{mmol} / 1$, Na 144 mmol/1 and SGPT 46 units.

Canad. Anaesth. Soc. J., vol. 28, no. 3, May 1981 


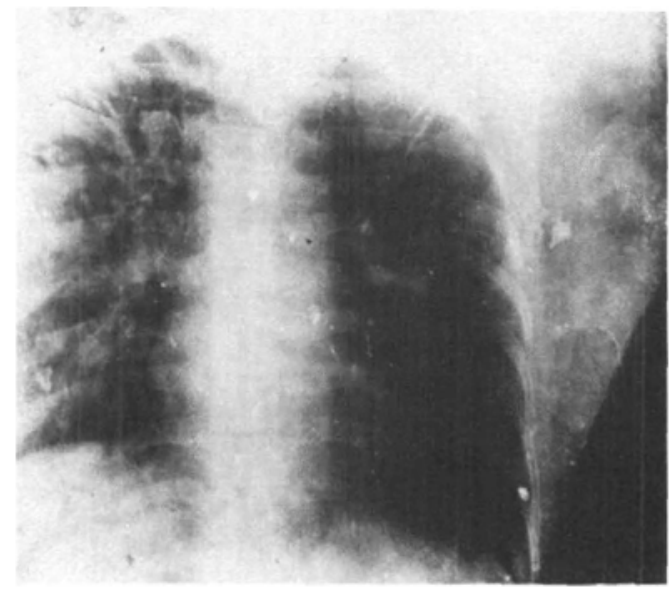

Figure 1 Chest $x$-ray showing avascular zone in the left lung base.

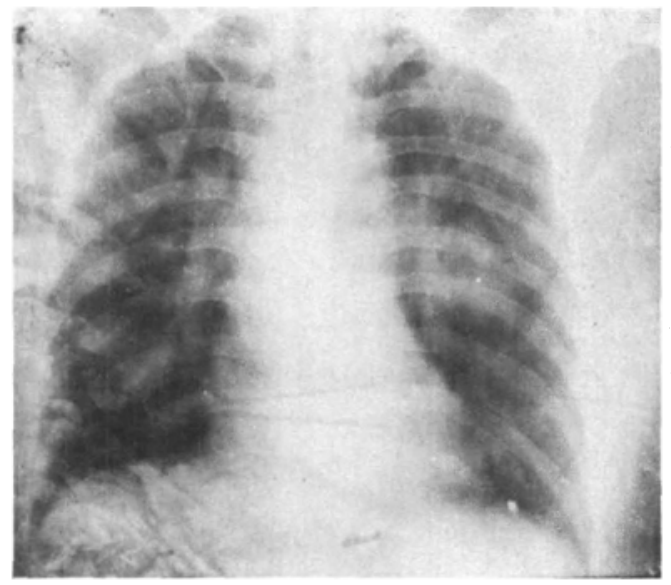

FIGURE 2 Chest x-ray two hours after that in Figure 1 , showing normal vascular markings in the left lung base.

Two hours later the avascular zone on the chest $\mathrm{x}$-ray and the LAHB on the electrocardiogram had disappeared (Figures $2 \& 3$ ). The trachea was now extubated. Blood pressure was $120 / 80$ $\mathrm{mmHg}$, pulse rate $130 / \mathrm{min}$, respiratory rate $32 /$ $\mathrm{min}$ and urine output $700 \mathrm{ml}$. Following these events the patient was given 10,000 units of heparin and was treated in the intensive care unit. She was discharged on the third day.

\section{Discussion}

Pulmonary embolism during anaesthesia is very rare. ${ }^{3,4}$ It is more common in obese and elderly individuals. Prolonged illness, debility, immobilization in bed and heart disease are the

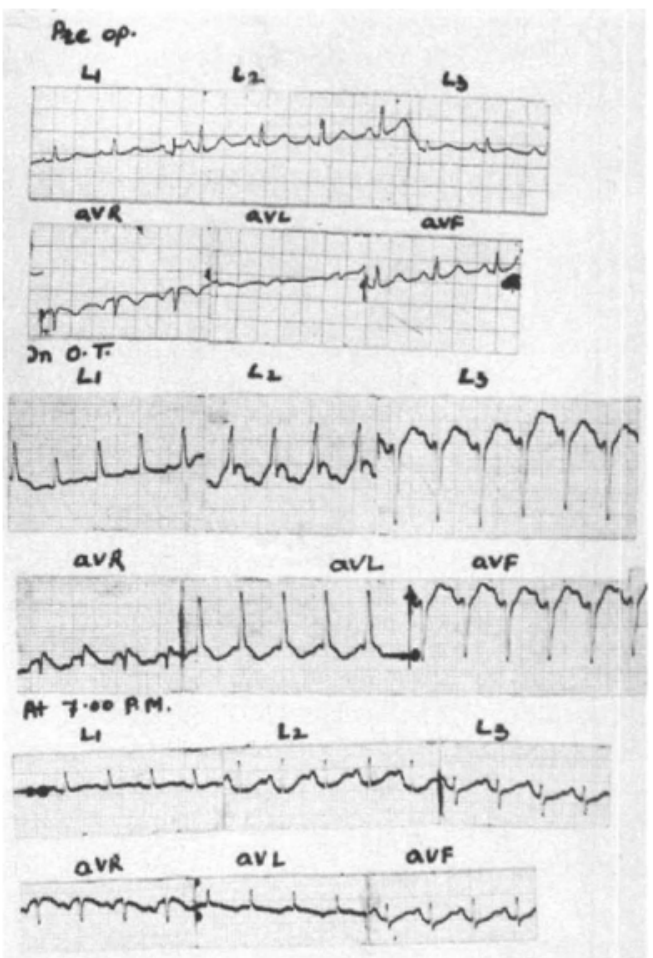

Figure 3 Electrocardiogram before operation, at the time of diagnosis of pulmonary embolism and after treatment and recovery.

predisposing factors. Our patient was obese, hypertensive and immobilized preoperatively for nearly one month.

Following intravenous d-tubocurarine the blood pressure dropped from 150 to $120 \mathrm{mmHg}$ systolic, and after positioning it fell to $70 \mathrm{mmHg}$ and cardiac arrest ensued. At the same time there was resistance to inflation of the chest and on ausculatation rhonchi were heard. This hypotension and bronchoconstriction could have been due to d-tubocuratine and related to ganglion blockade or histamine release. So at first it was concluded that this acute hypotension was due to d-tubocurarine or left ventricular failure. But when the chest $x$-ray showed ischaemia of the base of the left lung a diagnosis of pulmonary embolism was confirmed. Reflex bronchospassm might have occurred, which was more on the left side, and which is thought to be a response to a low carbon dioxide output from the non-perfused lung or the constrictive action of serotonin released by lysis of platelets at or near the site of embolization. The hypotension, tachycardia, cyanosis, bronchial sounds (râles and rhonchi) on 
the left side, the electrocardiographic findings of the left anterior hemiblock and the avascular left lower lung on $\mathrm{x}$-ray confirmed the diagnosis of pulmonary embolism.

The electocardiogram showed left anterior hemiblock, left axis deviation and deep $S$ waves in $\mathrm{L}_{3}$ and avf which disappeared with the relief of symptoms (Figure 3).

Arterial oxygen tension is usually normal but mixed expired and alveolar carbon dioxide often fall, indicating increase in dead space.

The signs of pulmonary embolism under anaesthesia may be a temporary phenomenon, depending on the size of the embolus and the size of the pulmonary artery which is obstructed, as well as the number of emboli. The second chest $x$-ray showed disappearance of the ischaemic zone in the base of the left lung and the patient improved clinically at the same time (Figure 2).

If there is no infarction, intravenous fibrinolysis can occur and the affected segment can return to a normal state. The rate of recovery depends to a significant degree on the previous state of health of the lung. As this patient had no preoperative chest problems, she recovered quickly within two hours. The immediate prognosis of massive pulmonary embolism is grave, 75 per cent of the patients dying within the first hour. Should the patient survive the first hour, the immediate risk declines rapidly, the main risk being the incidence of further emboli. This patient was heparinized with 10,000 units six hourly to prevent further embolization.

\section{ACKNOWLEDGEMENT}

We are indebted to Dr. M.S. Kekre for permitting use of hospital records.

\section{REFERENCES}

1. PrICE's Textbook of the practice of Medicine 1978-12th edition. Edited by Sir Ronald Bodley Scott. ECBS \& Oxford University Press page No. 803.

2. Betty, J. Bamforth, et al. A Case Report, Massive Pulmonary Embolism. Anaesthesiology 24: 590 (1963).

3. Enright, A.C., Quartey, G.R.C. \& McQueen, J.D. Pulmonary embolism during operation. Canad. Anaesth Soc. J. 27: 65 (1980).

4. Mangano, Dennis T. Immediate haemodynamic and pulmonary changes following pulmonary thromboembolism. Anaesthesiology, 52: 173, 1980.

5. Stein, P.D. et al. The electro-cardiogram in acute pulmonary embolism. Prog. Cardiovascular Dis. 17: $247-257$ (1975).

\section{RÉSUMÉ}

Les auteurs rapportent un cas d'embolie pulmonaire survenue sous anesthésie et s'étant manifestée après avoir installé une malade en position pour une discoïdectomie lombaire. Il s'agissait d'une malade obèse et hypertendue qui avait été immobilisée un mois avant l'intervention. La complication a été reconnue précocément et la malade a pu être traitée avec succès. 